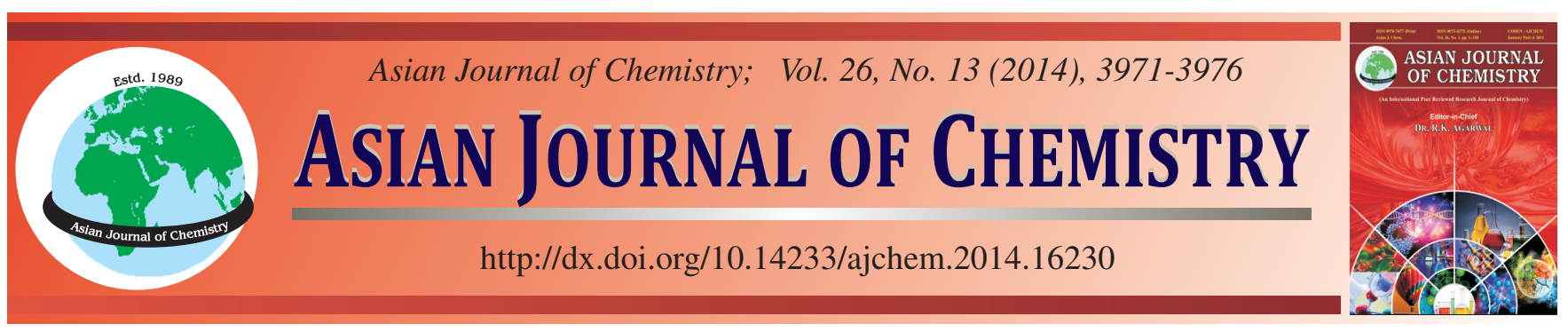

\title{
Controllable Synthesis of Calcium Carbonate with Different Morphologies and Phases Assisted by F127
}

\author{
Xueliang Rong ${ }^{*}$, Ming Yang, Qiao Huang and Pin ZhaO
}

School of Transportation, Southeast University, Nanjing 210096, P.R. China

*Corresponding author: Fax: +86 25 83795406; Tel: +86 25 83794100; E-mail: rongyihit@126.com

\begin{abstract}
Spica-like vaterite and nanorod-bundles aragonite have been synthesized through a precipitation route assisted by triblock copolymer $\mathrm{EO}_{106} \mathrm{PO}_{70} \mathrm{EO}_{106}(\mathrm{~F} 127)$. The as-prepared $\mathrm{CaCO}_{3}$ samples are characterized by X-ray powder diffraction, scanning electron microscopy and high-resolution transmission electron microscopy. The effect of copolymer on the morphologies of $\mathrm{CaCO}_{3}$ samples is investigated by SEM, compared with the products obtained without adding copolymer. The possible formation mechanism of the calcium carbonate with different morphologies was discussed. It was supposed that the copolymer F127 made the morphologies of calcium carbonate more uniform. The photoluminescence properties of $\mathrm{CaCO}_{3}: \mathrm{Eu}^{3+}$ red phosphors were also investigated.
\end{abstract}

Keywords: Crystal morphology, Crystal growth, Calcium carbonate, Phosphor.

\section{INTRODUCTION}

Calcium carbonate is a representative bio-mineral system and also important industrial substances used in industry for cement, paper, etc. There are three anhydrous crystalline phases, rhombo-centered hexagonal calcite, primitive hexagonal aragonite and primitive orthorhombic vaterite. Calcite is the most stable phase at ambient temperature and pressure in thermodynamics and calcite and aragonite are the main biologically formed $\mathrm{CaCO}_{3}$ polymorphs ${ }^{1,2}$. Vaterite, a less stable polymorph, is expected to have potential applications for various purposes due to its properties such as high dispersion, high solubility, high specific surface area and lower specific gravity compared with the other two crystalline forms ${ }^{3}$. Normally, these crystals in organisms are found assembled into different hierarchical structures with intriguing properties ${ }^{4}$. Therefore, the control of crystalline phases and morpho-logies of $\mathrm{CaCO}_{3}$ is of great significance and has received much attention $^{5-7}$.

Many different crystallization methods have been chosen to control the crystalline phases and morphologies of $\mathrm{CaCO}_{3}$, such as vapor diffusion method ${ }^{8}$, solvothermal $\operatorname{method}^{9}$ and microwave-assisted synthesis ${ }^{10}$. Among these methods, the precipitation route is a more facile way. Various additives may have great effects on the crystallization of calcium carbonate, e.g., ionic liquids ${ }^{11}, \mathrm{PSS}^{12}$ and the mixed water and organic solvents, such as ethanol ${ }^{13}$ and pyridine ${ }^{14}$. Among the additives, block copolymers with versatility have been used as effective crystal growth modifiers, which produce homogeneous populations of particles frequently with unusual morphologies ${ }^{15-17}$, such as double-hydrophilic compolymer.

Inorganic phosphors doped with rare earth ions have attracted much attention due to the remarkable luminescent properties and applications, commonly used for color display and lamp industry ${ }^{18}$. Trivalent europium $\left(\mathrm{Eu}^{3+}\right)$ as an efficient red luminescent activator was widely studied in terms of its electronic transitions from the lowest ${ }^{5} \mathrm{D}_{0}$ excited state to ${ }^{7} \mathrm{~F}_{\mathrm{J}}(\mathrm{J}=$ $0,1,2,3,4)$ ground state, strongly depending on the local environments in host lattices ${ }^{19}$. Until now, a small quantity of literatures concerning the luminescence properties of carbonate minerals doped with rare earth ions were documented ${ }^{20}$.

Even though various novel calcium carbonate crystals in the presence of numerous crystal modifiers have been synthesized, such as needle-like calcite particles generated using an acrylate-styrene copolymer ${ }^{21}$. To the best of our knowledge, few work has been done with a focus on the controllable synthesis of the spica-like vaterite and nanorod-bundles aragonite assisted by triblock copolymer F127 and further investigated the luminescent properties of the as-prepared $\mathrm{CaCO}_{3}$ doped with $\mathrm{Eu}^{3+}$ ions. In this work, we proposed a facile route to get the spica-like vaterite and rod-bundles aragonite and the growth mechanism was investigated. By using F127 and varying the reaction temperature, calcium carbonate with different crystal phase and morphologies were obtained and the transformation process was studied by XRD, SEM and TEM characterization. The luminescent properties of $\mathrm{CaCO}_{3}: \mathrm{Eu}^{3+}$ phosphors with different morphologies were also studied. 


\section{EXPERIMENTAL}

The starting materials utilized are calcium chloride, sodium carbonate anhydrous (analysis purity grade, Nanjing Chemical Reagent Co. Ltd.). F-127 ( $\mathrm{EO}_{106} \mathrm{PO}_{70} \mathrm{EO}_{106}, \mathrm{MW}=12600$, Product no. P2443-250G) was purchased from Aldrich and used as received without further purification. Distilled water was used throughout the experiment.

Synthesis of $\mathrm{CaCO}_{3}$ : In a typical process, $0.9 \mathrm{~g} \mathrm{~F} 127$ was dissolved in $23 \mathrm{~mL}$ ethanol and $0.01 \mathrm{~mol} \mathrm{CaCl}_{2}$ was dissolved in $20 \mathrm{~mL}$ deionized water and then the solution of $0.01 \mathrm{~mol} \mathrm{Na}_{2} \mathrm{CO}_{3}$ in $10 \mathrm{~mL}$ deionized water was dropped in it at room temperature. Then, the reaction solution was heated at room temperature and $80{ }^{\circ} \mathrm{C}$ for different times. When the reaction was finished, the precipitate was filtered and washed with ethanol and water for several times and the products were dried in desiccator for $24 \mathrm{~h}$ at room temperature. To get the calcite samples, the as-prepared products were calcined at $450{ }^{\circ} \mathrm{C}$ for $4 \mathrm{~h}\left(1^{\circ} \mathrm{C} \mathrm{min}{ }^{-1}\right.$ under air $)$. A control experiment was carried out without using F127, while other conditions were unchanged. The reaction is the deposition reaction between $\mathrm{CaCl}_{2}$ and $\mathrm{Na}_{2} \mathrm{CO}_{3}$ and the chemical reaction equation is as follows:

$$
\mathrm{CaCl}_{2}+\mathrm{Na}_{2} \mathrm{CO}_{3} \longrightarrow \mathrm{CaCO}_{3}+2 \mathrm{NaCl}
$$

Synthesis of $\mathrm{CaCO}_{3}$ doped with $\mathrm{Eu}^{3+}$ ions: $\mathrm{CaCO}^{3}: \mathrm{Eu}^{3+}$ phosphors were obtained through adding $0.2 \mathrm{mmol} \mathrm{Eu}\left(\mathrm{NO}_{3}\right)_{3}$ prepared by dissolving $\mathrm{Eu}_{2} \mathrm{O}_{3}$ powders in concentrated $\mathrm{HNO}_{3}$ solution into the above mentioned solution while other reaction parameters were kept unchanged.

\section{Characterization}

The crystalline phase of the products were identified using $\mathrm{X}$-ray diffraction (XRD; Ultima III, Rigaku) with $\mathrm{CuK}_{\alpha}$ radiation $(\lambda=0.154 \mathrm{~nm}, 40 \mathrm{kV}, 40 \mathrm{~mA})$ and a scan rate of $10^{\circ} \mathrm{min}^{-1}$. The morphology and microstructure of the samples were observed by a field emission scanning electron microscope (FE-SEM; NOVA230, FEI Ltd.) with accelerating voltage of $10 \mathrm{kV}$ and a high resolution transmission electron microscope (TEM; JEM-2100, 200 kV, JEOL Ltd.). Photoluminescence (PL) properties of the as-prepared $\mathrm{CaCO}_{3}$ : $\mathrm{Eu}^{3+}$ phosphors were detected by a spectrofluorometer (VARIAN, Cary Eclipse, USA) at room temperature.

\section{RESULTS AND DISCUSSION}

Modulation of the crystalline phase of calcium carbonate: Wide-angle XRD was used to identify the crystalline phase of the as-prepared samples and the results are presented in Fig. 1. The XRD patterns of the samples prepared in the presence of the copolymer F127 at different temperatures (Fig. 1 a-d) show vaterite, aragonite and calcite crystals, respectively. The XRD pattern of the sample prepared at room temperature (Fig. 1a) shows that the diffraction peaks are in good agreement with JCPDS No. 33-0268, vaterite crystals. Fig. 1b shows the XRD pattern of the sample prepared at $80^{\circ} \mathrm{C}$ for $60 \mathrm{~min}$, which result shows the mixed crystalline phases of vaterite (JCPDS No. 33-0268) and aragonite crystals (JCPDS No. 41-1475). Fig. 1c shows the XRD pattern of the sample prepared at $80{ }^{\circ} \mathrm{C}$ for $3 \mathrm{~h}$, which result shows that the diffraction peaks are in good agreement with JCPDS No. 41-1475, aragonite crystals. Fig. 1d shows the XRD pattern of the sample prepared at $80{ }^{\circ} \mathrm{C}$ for $3 \mathrm{~h}$ and then calcined at $450{ }^{\circ} \mathrm{C}$, which result shows that the diffraction peaks are in good agreement with JCPDS No. 47-1743, calcite crystals. With the increase of reaction temperatures and times, the crystalline phases of the as-prepared samples vary from vaterite to aragonite and then calcite after thermal treatment. Vaterite and aragonite are metastable in nature, with vaterite being particularly unstable $\mathrm{e}^{22}$. Because calcite is the most thermodynamically stable form of $\mathrm{CaCO}_{3}$ under ambient conditions $^{22}$, it forms after the thermal treatment under high temperature. The crystalline phases of $\mathrm{CaCO}_{3}$ can be controlled through changing the reaction temperatures and times in the system in the presence of F127.

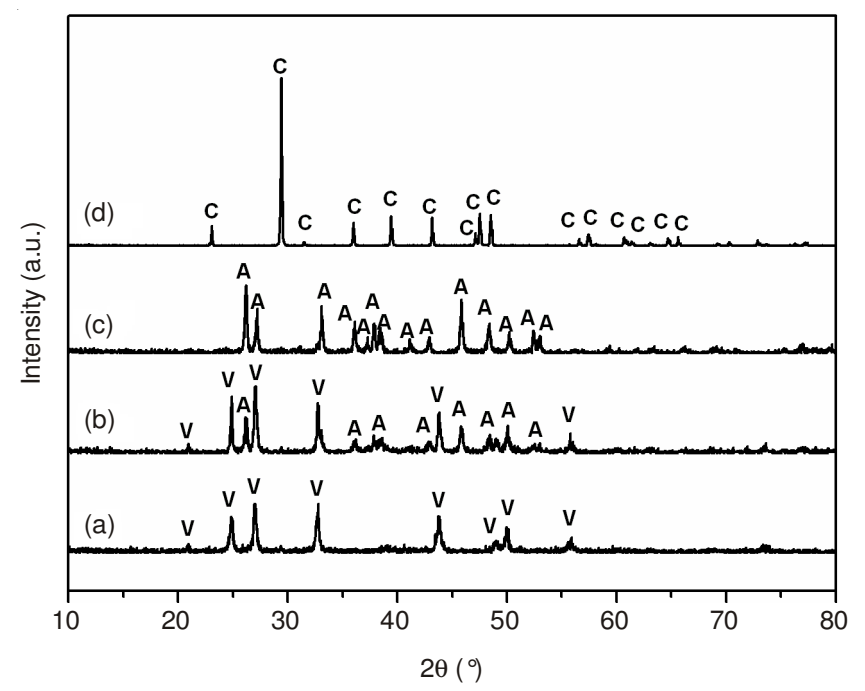

Fig. 1. XRD patterns of the samples prepared by using F127 at different reaction times; (a) $20 \mathrm{~min}$ at room temperature; (b) $60 \mathrm{~min}$ at 80 ${ }^{\circ} \mathrm{C}$; (c) $3 \mathrm{~h}$ at $80{ }^{\circ} \mathrm{C}$ and (d) the sample calcined at $450{ }^{\circ} \mathrm{C}$ for $4 \mathrm{~h}$

Modulation of the morphologies of calcium carbonate: The morphologies of the as-prepared samples are characterized by SEM and the results are shown in Fig. 2. From Fig. 2ab, spica-like vaterite crystals prepared at room temperature were observed. With the increase of reaction temperature, spicalike vaterite and rod-bundles aragonite (Fig. $2 \mathrm{~cd}$ ) prepared in the presence of F127 were formed. From Fig. 2 ef, spica-like vaterite crystals disappear and nanorod-bundles aragonite grow in larger sizes. After the thermal treatment, the calcite crystals show the wormlike morphology (Fig. 2 gh).

The TEM images taken on the as-prepared $\mathrm{CaCO}_{3}$ samples provide further information on the crystallization (Fig. 3). It can be observed from Fig. 3a that the as-prepared vaterite are composed of nanoparticles about $200 \mathrm{~nm}$ in size. The highresolution TEM (HRTEM) image recorded on the edge of the nanoparticle shows that the sample is structurally uniform with an interplanar spacing of about $0.273 \mathrm{~nm}$, which corresponds to the lattice spacing for the (114) faces of vaterite (Fig. 3a, inset). From Fig. 3b, the aragonite crystals are bundles of nanorods and the diameter of the nanorod is about $500 \mathrm{~nm}$. From Fig. 3b, inset, the lattice planes spacing is $0.270 \mathrm{~nm}$, which corresponds to the (012) crystal planes of aragonite. SAED patterns shown in Fig. $3 a$ and b, inset indicate the well 

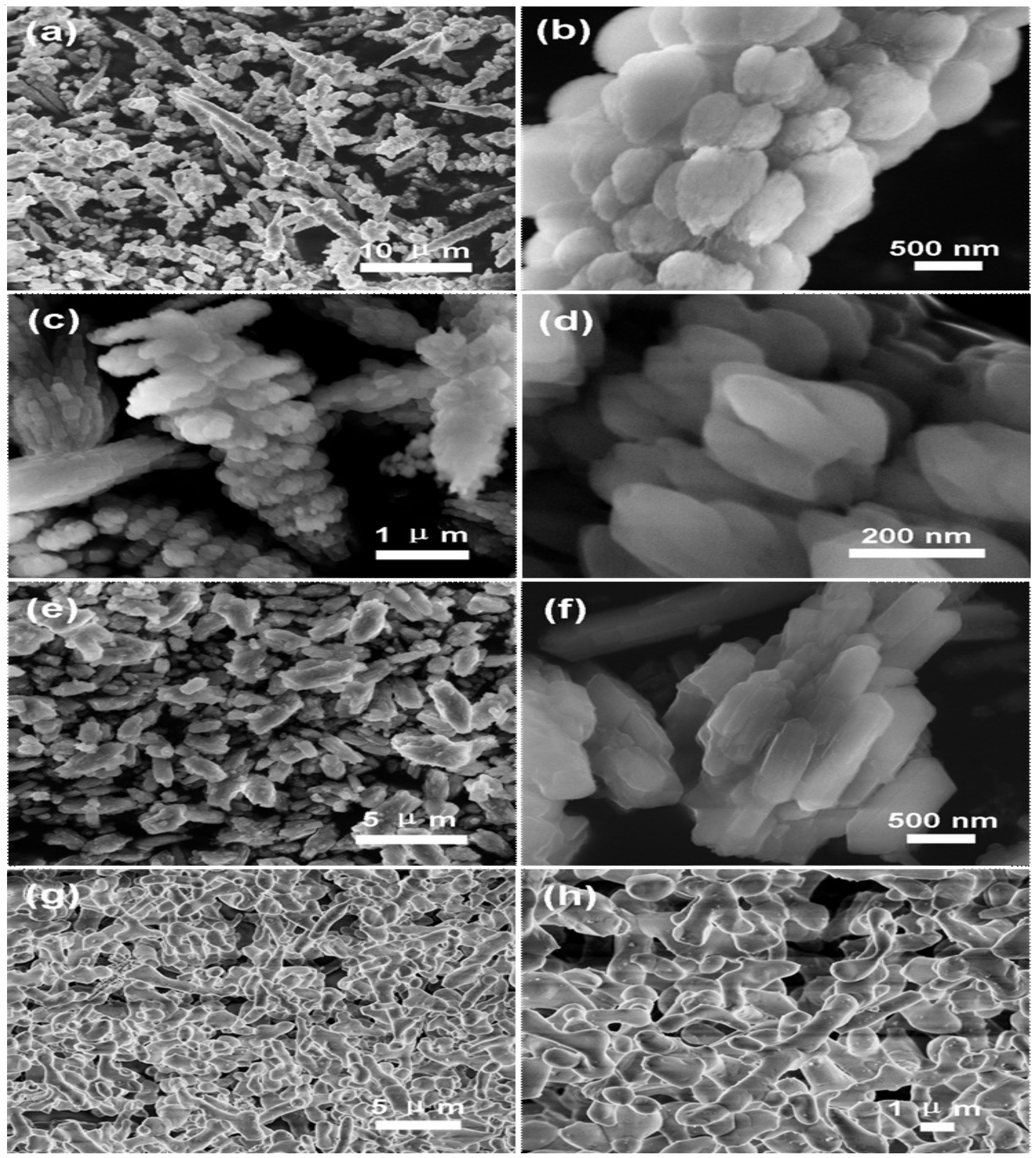

Fig. 2. SEM images of calcium carbonate prepared with $\mathrm{F} 127$ at different reaction times; (a and b) $20 \mathrm{~min}$ at room temperature; (c and d) $60 \mathrm{~min}$ at $80{ }^{\circ} \mathrm{C}$; (e and f) $3 \mathrm{~h}$ at $80{ }^{\circ} \mathrm{C}$; (g and h) the sample (e) calcined at $450{ }^{\circ} \mathrm{C}$ for $4 \mathrm{~h}$

crystalline $\mathrm{CaCO}_{3}$ samples and show the polycrystalline nature. The morphologies of the $\mathrm{CaCO}_{3}$ samples can be controlled through changing the reaction temperatures and times in the system in the presence of F127. Moreover, a continuous morphological and structural transition between these crystals can be observed, offering considerable insight into the mechanism of formation of calcium carbonate particles in the presence of triblock copolymer F127.
Effects of F127 on the phases and morphologies of $\mathrm{CaCO}_{3}$ : For analyzing the effects of $\mathrm{F} 127$ on the phases and morphologies of $\mathrm{CaCO}_{3}$ in this system, the $\mathrm{CaCO}_{3}$ samples prepared in the absence of the copolymer F127 are characterized by XRD and SEM. The results are shown in Figs. 4 and 5, respectively. From Fig. 4, mixed crystalline phases of vaterite, aragonite and calcite appeared when the reaction was processed in the absence of $\mathrm{F} 127$ at whether room temperature or $80^{\circ} \mathrm{C}$. 

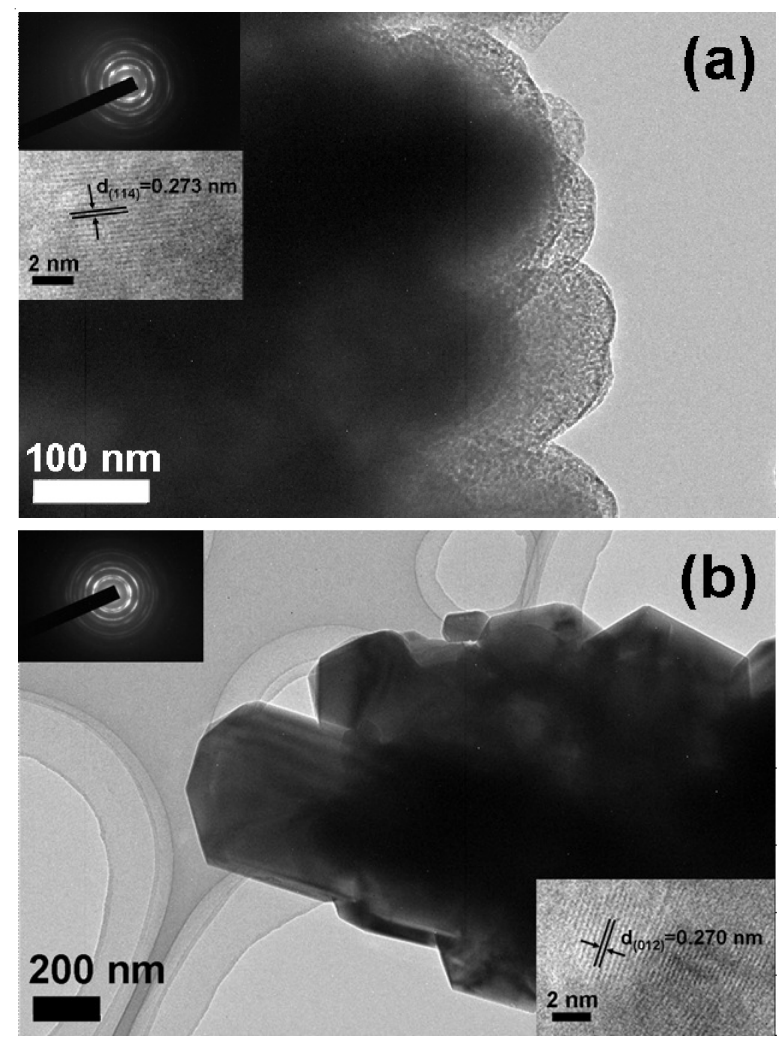

Fig. 3. TEM images of the as-prepared samples with F127 at different reaction times; (a) $20 \mathrm{~min}$ at room temperature, high magnification TEM image and corresponding SAED pattern (inset of Fig. 3a); (b) $3 \mathrm{~h}$ at $80^{\circ} \mathrm{C}$, high magnification TEM image and corresponding SAED pattern (inset of Fig. 3b)
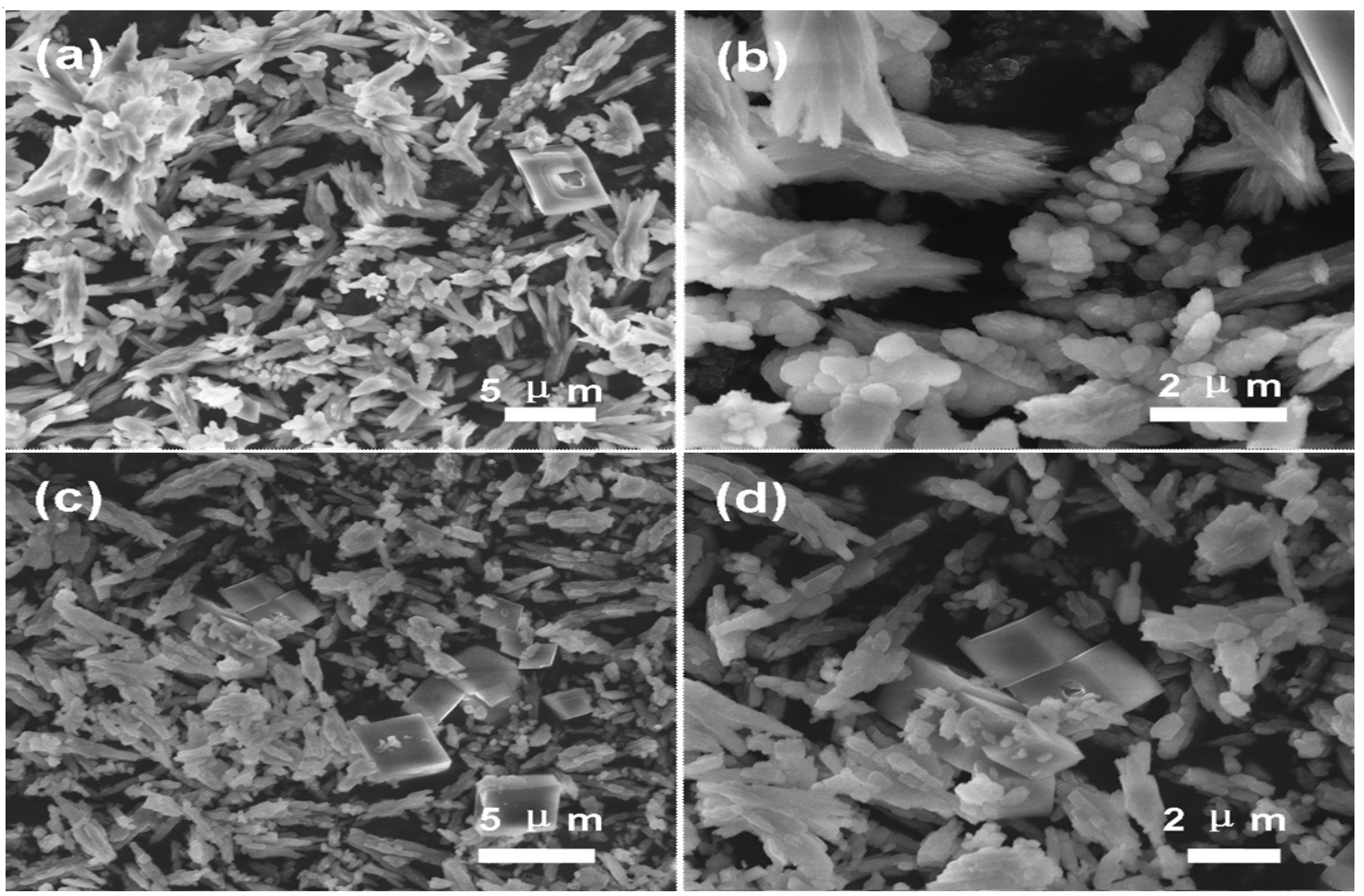

Fig. 5. SEM images of the samples prepared without F127 at different reaction times, (a, b) 20 min at room temperature; (c, d) $3 \mathrm{~h}$ at $80{ }^{\circ} \mathrm{C}$ 
and $\mathrm{d}$, rhombohedral and some irregularly morphological $\mathrm{CaCO}_{3}$ particles are observed. Compared with the SEM images of the samples prepared in the presence of $\mathrm{F} 127$ (Fig. 2), uniform $\mathrm{CaCO}_{3}$ particles are not obtained in the synthesis system without F127. And, the polycrystalline $\mathrm{CaCO}_{3}$ particles may be formed by aggregation of the particles proceeding more rapidly than growth of individual particles retarded further growth by the temporary stabilization of the primary units by interaction with the block copolymers ${ }^{17}$. Thus, the uniform $\mathrm{CaCO}_{3}$ particles with various morphologies and different crystalline phases are prepared through the facile precipitation route assisted by F127.

Modulation mechanism of the phases and morphologies of $\mathrm{CaCO}_{3}$ : Further analysis of the modulation mechanism of morphologies and phases, the sample prepared at $80{ }^{\circ} \mathrm{C}$ for 60 min was characterized by TEM. From Fig. 6a, the spikelike vaterite dissolve into smaller size (about $150 \mathrm{~nm}$ ) compared with the sample obtained at room temperature when the growth time increases to $60 \mathrm{~min}$. Individual rod is clearly observed with rough surfaces and these architectures are built from $\mathrm{CaCO}_{3}$ nanoparticles (Fig. 6b). Once the $\mathrm{CaCO}_{3}$ nuclei are formed, they are active because of their high surface energy and tend to aggregate growth, leading to the formation of larger aggregation to minimize the surface energies, which is similar to the formation of the $\mathrm{SnO}_{2}$ nanorods ${ }^{23}$. The aggregation growth process can occur by random aggregation and then the Ostwald ripening process occurs which involves the growth of larger crystals at the expense of smaller ones ${ }^{24}$.
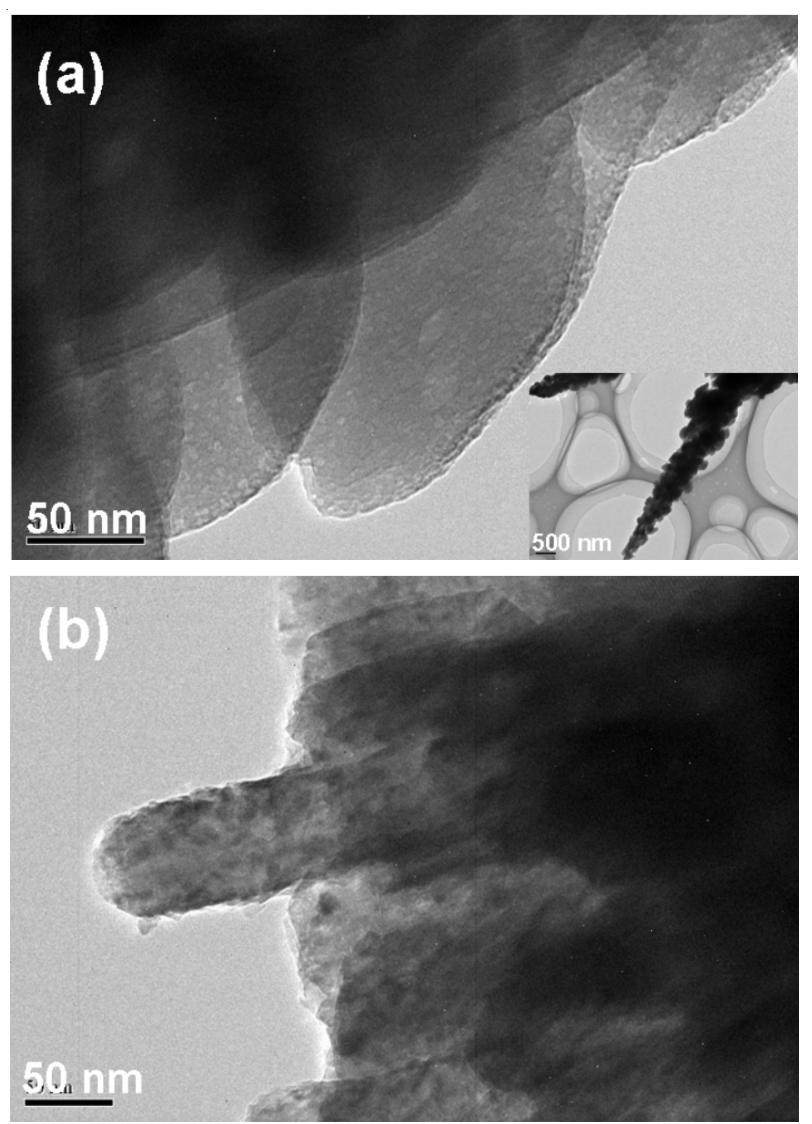

Fig. 6. TEM images of the as-prepared samples with $\mathrm{F} 127$ at $80{ }^{\circ} \mathrm{C}$ for 60 min; (a) spike-like vaterite, low-magnification image (a, inset) and (b) nanorod-bundles aragonite
The proposed formation mechanism of $\mathrm{CaCO}_{3}$ with controlled morphologies and crystalline phases is presented in Fig. 7. The primary spike-like vaterite particles may be first formed by the aggregation of nanoparticles. And then with the increase of the reaction temperature, the phase transformation of $\mathrm{CaCO}_{3}$ from vaterite to aragonite happened. The spike-like vaterite may dissolve into nanoparticles and re-aggregate to form nanorods and the nanorods assemble to aragonite nanorodbundles. With the increase of the reaction time, the nanorods grow larger through the Ostwald ripening process. All the above facts suggest an inhibition of calcite crystal growth in the reaction system by F127.

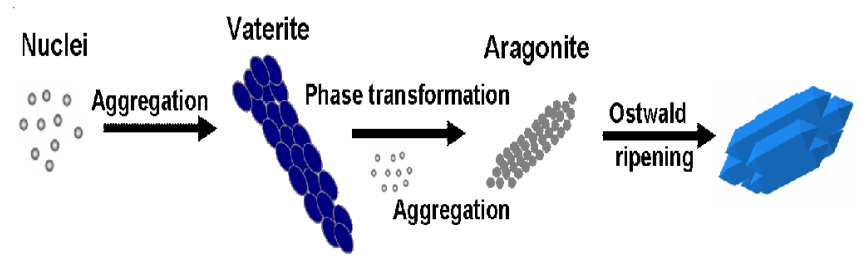

Fig. 7. Schematic illustration of the proposed modulation mechanism of the morphologies of the as-prepared $\mathrm{CaCO}_{3}$

Considering here the vaterite surface characteristics, it is likely that during the growing step of calcium carbonate crystals, the copolymer adsorbs on some crystalline plane of $\mathrm{CaCO}_{3}$, reducing hence their surface energies and stabilizing the vaterite surfaces. At higher reaction temperature, F127 also react as the stabilizing regent for aragonite. Based on the above results, F127 is more beneficial to keep aragonite stable than vaterite at higher temperature in the synthetic system. Thus, in this reaction system, the influence of F127 on the crystal growth of calcium carbonate is in two ways: on the one hand, F127 as a kind of nonionic copolymer can stabilize the vaterite or aragonite phases of calcium carbonate, which are less stable at usual condition compared with calcite. On the other hand, the morphologies of vaterite and aragonite are uniform and assembled with nanoparticles or nanorods, which may be caused by the existence of F127 and the induced corresponding aggregation of nanopaticles or nanorods. Thus, the calcium carbonate with controllable crystalline phases and morphologies are formed.

Photoluminescence properties of $\mathrm{CaCO}_{3}$ doped with $\mathbf{E u}^{3+}$ : Photoluminescence spectra of $\mathrm{CaCO}_{3}$ doped with $\mathrm{Eu}^{3+}$ are shown in Fig. 8. Although the discrepancy of the ion radii between $\mathrm{Eu}^{3+}\left(\mathrm{r}_{\mathrm{i}}=0.95 \AA\right)$ and $\mathrm{Ca}^{2+}\left(\mathrm{r}_{\mathrm{i}}=1 \AA\right)$ is to some extent, $\mathrm{CaCO}_{3}: \mathrm{Eu}^{3+}$ red phosphors have been prepared at room temperature ${ }^{20}$. That is to say, $\mathrm{Eu}^{3+}$ ions can partially replace the $\mathrm{Ca}^{2+}$ ions in the growth and crystallization processes of phosphors. Fig. 8 depicts the typical red photoluminescence from $\mathrm{Eu}^{3+}$ ions towards the as-obtained $\mathrm{CaCO}_{3}: \mathrm{Eu}^{3+}$ phosphor by designating the excitation wavelength at $254 \mathrm{~nm}$. A series of sharp bands at 573, 598, 608, 660 and $681 \mathrm{~nm}$ are assignable to the characteristic transitions of $\mathrm{Eu}^{3+}$ from lowest ${ }^{5} \mathrm{D}_{0}$ excited state ${ }^{7} F_{j}(j=0,1,2,3$ and 4$)$ ground state ${ }^{20}$. The peak intensity at 573,598 and $608 \mathrm{~nm}$ decreases when the phosphors evolved from spica-like vaterite to nanorod-bundles aragonite and then to wormlike calcite, which may be due to the different microstructures. 


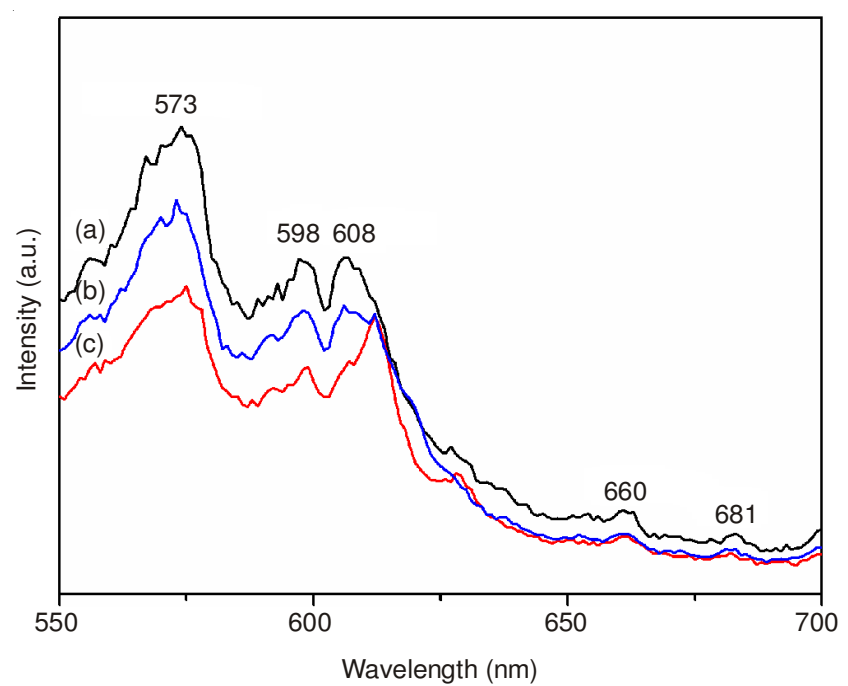

Fig. 8. Photoluminescence spectra of the as-prepared $\mathrm{CaCO}_{3}$ doped with $\mathrm{Eu}^{3+}$ at room temperature; (a) spike-like vaterite; (b) nanorodbundles aragonite and (c) wormlike calcite, the emission laser wavelength at $\lambda_{\mathrm{ex}}=254 \mathrm{~nm}$

\section{Conclusion}

Calcium carbonate particles with controlled morphologies and crystalline phases are synthesized by a precipitation route assisted by F127. Through changing the reaction temperatures, spica-like vaterite and nanorod-bundles aragonite are obtained and wormlike calcite is also prepared after thermal treatment. It was supposed that the existence of F127 made the morphologies of calcium carbonate more uniform. $\mathrm{CaCO}_{3}$ : $\mathrm{Eu}^{3+}$ red phosphor has been prepared and the photoluminescence properties were studied.

\section{ACKNOWLEDGEMENTS}

This work is supported by the National Natural Science Foundation of China (No. 51208102).

\section{REFERENCES}

1. G.T. Zhou, J.C. Yu, X.C. Wang and L.Z. Zhang, New J. Chem., 28, 1027 (2004).

2. W.T. Hou and Q.L. Feng, Cryst. Growth Des., 6, 1086 (2006).

3. K. Naka, Y. Tanaka and Y. Chujo, Langmuir, 18, 3655 (2002).

4. J.G. Yu, M. Lei, B. Cheng and X.J. Zhao, J. Solid State Chem., 177, 681 (2004)

5. H. Cölfen and M. Antonietti, Angew. Chem. Int. Ed., 44, 5576 (2005).

6. J.H. Zhan, H.P. Lin and C.Y. Mou, Adv. Mater., 15, 621 (2003).

7. J. Aizenberg, A.J. Black and G.H. Whitesides, J. Am. Chem. Soc., 121, 4500 (1999).

8. A.W. Xu, W.F. Dong, M. Antonietti and H. Cölfen, Adv. Funct. Mater., 18, 1307 (2008).

9. Q. Li, Y. Ding, F.Q. Li, B. Xie and Y.T. Qian, J. Cryst. Growth, 236, 357 (2002).

10. Y.X. Chen, X.B. Ji and X.B. Wang, J. Cryst. Growth, 312, 3191 (2010).

11. Y. Zhao, Z.H. Chen, H.Y. Wang and J.J. Wang, Cryst. Growth Des., 9, 4984 (2009).

12. M. Yang, X.Q. Jin and Q. Huang, Colloids Surf. A, 374, 102 (2011).

13. L. Zhang, L.H. Yue, F. Wang and Q. Wang, J. Phys. Chem. B, 112, 10668 (2008).

14. Z.D. Nan, B.Q. Yan, X.Z. Wang, R. Guo and W.G. Hou, Cryst. Growth Des., 8, 4026 (2008).

15. S.-H. Yu and H. Cölfen, J. Mater. Chem., 14, 2124 (2004).

16. K.L. Robinson, J.V.M. Weaver, S.P. Armes, E.D. Marti and F.C. Meldrum, J. Mater. Chem., 12, 890 (2002).

17. A.N. Kulak, P. Iddon, Y.T. Li, S.P. Armes, H. Cölfen, O. Paris, R.M. Wilson and F.C. Meldrum, J. Am. Chem. Soc., 129, 3729 (2007).

18. C. Feldmann, T. Jüstel, C.R. Ronda and P.J. Schmidt, Adv. Funct. Mater., 13, 511 (2003).

19. T. Katsumata, K. Sasajima, T. Nabae, S. Komuro and T. Morikawa, J. Am. Ceram. Soc., 81, 413 (1998).

20. S.P. Bao, X.Y. Chen, Z. Li, B.J. Yang and Y.C. Wu, Cryst. Eng. Comm., 13, 2511 (2011).

21. L. Moore, J.D. Hopwood and R.J. Davey, J. Cryst. Growth, 261, 93 (2004).

22. H. Cölfen, Curr. Opin. Colloid Interface Sci., 8, 23 (2003).

23. D.F. Zhang, L.D. Sun, J.L. Yin and C.H. Yan, Adv. Mater., 15, 1022 (2003).

24. W. Ostwald, Z. Phys. Chem., 34, 495 (1900). 